ORIGINAL ARTICLE

\title{
Clusters of meningococcal disease in school and preschool settings in England and Wales: what is the risk?
}

\author{
K L Davison, N Andrews, J M White, M E Ramsay, N S Crowcroft, A A Rushdy, E B Kaczmarski, \\ P N Monk, J M Stuart
}

Arch Dis Child 2004;89:256-260. doi: 10.1136/adc.2003.031369

\begin{abstract}
See end of article for authors' affiliations

Correspondence to: Ms K L Davison,

Immunisation Department, HPA Communicable Disease Surveillance Centre, London NW9 5EQ, UK; kdavison@ hpa.org.uk
\end{abstract}

Accepted 27 June 2003

\begin{abstract}
Aims: To assess the risk of further cases in educational settings in order to inform policy on managing cases and clusters of meningococcal disease.

Methods: Between 1 April 1995 and 31 March 2001, surveillance in preschool and school settings in England and Wales identified 114 clusters of meningococcal disease. Twenty clusters were reported in preschool settings, 43 in primary, 46 in secondary, and five in independent schools. Seventy three clusters $(64 \%)$ consisted of two or more confirmed cases, of which 30 had two or more serogroup C cases. Following the introduction of the national meningococcal serogroup $C$ vaccination programme in 1999, no serogroup C clusters were observed between April 2000 and March 2001.

Results: The relative risk of further cases in the four weeks after a single case compared with the background rate was raised in all settings, ranging from RR 27.6 (95\% Cl 15.2 to 39.9) in preschool settings to RR 3.6 (95\% Cl 2.5 to 4.6 ) in secondary schools. Absolute risk estimates ranged from 70 / 100000 in preschool settings to $3.0 / 100000$ in secondary schools. The relative risk of clustering was similar for serogroup $B$ and $C$ strains. Most (68\%) second cases occurred within seven days of the first case.

Conclusions: Although there was a higher risk of further cases of meningococcal disease in schools and especially in preschool settings, it is not known whether widespread antibiotic use after single cases reduces risk of further cases and if there is a real risk of harm. Evidence of risk reduction is needed to inform public health policy.
\end{abstract}

$\mathrm{S}$ ingle cases and clusters of meningococcal disease in school and preschool settings generate high levels of public anxiety, especially when cases die. This often results in pressure on public health professionals to offer antibiotics for prophylaxis on a wider scale than can be justified on the available evidence. ${ }^{1-4}$

Guidance on the management of meningococcal disease in England and Wales issued in 1995 and 1997 recommended antibiotic prophylaxis only to close household contacts after a single case, with more widespread use in educational settings after two or more cases. ${ }^{56}$ In order to inform new evidence based guidance for the $\mathrm{UK}^{7}$ estimates of risk in different settings ${ }^{8}$ needed updating, especially in view of the high incidence of meningococcal disease caused mainly by serogroup C since $1995 .{ }^{\circ}$

We estimated the risk of clusters occurring in preschool settings and in primary, secondary, and independent (private) schools in England and Wales from 1995 to 2001.

\section{METHODS}

Definitions of cases and clusters

These are provided in the box.

\section{Data sources}

Since 1999 consultants in communicable disease control have reported clusters of meningococcal disease in England and Wales through an enhanced surveillance scheme using a standard questionnaire. ${ }^{10}$ Data collected includes demographic and microbiological details of the cases, school and class size, and information on how the clusters were managed. Before 1999, a series of retrospective postal surveys were carried out to collect this data. Cases in these clusters were matched to isolates and clinical specimens referred to

\section{Definitions of cases and clusters}

- A confirmed case: meningitis, septicaemia, or other invasive disease AND at least one of: isolation of Neisseria meningitidis from a sterile site; Gram negative diplococci in CSF; or DNA detection of $\mathrm{N}$ meningitidis through PCR; meningococcal specific antigen in blood, CSF, or urine

- A probable case: meningitis, septicaemia or other invasive disease in the absence of any laboratory confirmation where meningococcal infection was the most likely cause

- A cluster: 2 or more cases of meningococcal disease (confirmed or probable) within 4 weeks in children attending the same educational institution

- A confirmed cluster: 2 or more confirmed cases of meningococcal disease within 4 weeks in children attending the same educational institution

- A probable cluster: 1 confirmed case and 1 or more probable cases of meningococcal disease; or 2 or more probable cases within 4 weeks in children attending the same educational institution

\section{Exclusions}

Clusters of 2 or more cases in siblings

the HPA Meningococcal Reference Unit (MRU) to provide more information on phenotype and genotype. ${ }^{8}$

School denominator data, as at January 1998, was obtained from the Department for Education and 
Table 1 Estimated rates of meningococcal disease in preschool and school settings in England and Wales from April 1995 to March 2001

\begin{tabular}{|c|c|c|c|c|c|c|}
\hline Setting & Age (years) & $\begin{array}{l}\text { Background rate of } \\
\text { meningococcal disease* } \\
\text { (per } 100,000 / \text { year) }\end{array}$ & $\begin{array}{l}\text { Adjusted background } \\
\text { rate (per } 100000 / \text { year) } \dagger\end{array}$ & $\begin{array}{l}\text { Number of } \\
\text { premises }\end{array}$ & $\begin{array}{l}\text { Number of } \\
\text { students }\end{array}$ & $\begin{array}{l}\text { Average } \\
\text { number }\end{array}$ \\
\hline Preschool & $2-4$ & 18.39 & 26.21 & 24053 & $665074 \ddagger$ & 28 \\
\hline Primary & $4-10$ & 6.56 & 26.21 & 19985 & 4754337 & 238 \\
\hline Secondary & $11-16$ & 6.00 & 11.17 & 3795 & 3274674 & 863 \\
\hline Independent & $4-18$ & 6.85 & 9.02 & 2284 & 566038 & 248 \\
\hline
\end{tabular}

*Meningococcal Reference Unit data for laboratory confirmed cases, background average over the six years (increased from enhanced surveillance confirmed). tIncludes two correction factors: (1) correction for excluding summer holidays; (2) correction for probable cases from enhanced surveillance.

$\ddagger$ Number of attendees and places combined as number of children not available for children under 5 years in all preschool nurseries.

Employment and the National Assembly for Wales. Numbers of children were not available for playgroups and day nurseries, so numbers of places provided were used as a proxy.

\section{Analysis}

The expected number of clusters was calculated for each setting from data on the number of premises, average number of students, and age stratified weekly totals of cases of meningococcal disease from MRU data during the study period. The MRU data were first adjusted for under-reporting and unconfirmed cases (using correction factors derived from the enhanced surveillance programme) and for underascertainment of linked cases that may have occurred during summer holidays (table 1).

Relative and absolute risks were calculated for all clusters in each setting (preschool, primary, secondary, and independent schools). Relative risk was defined as the risk of meningococcal disease to an individual in a given time period following a case in the same setting compared to the background risk in the same period in England and Wales. Absolute risk was defined as the risk to the individual of meningococcal disease in a given time period following a case in the same setting. All risks and 95\% confidence intervals were calculated using GLIM. ${ }^{11}$

Risks were also calculated in each setting for a confirmed cluster following an initial confirmed case and the risk of a serogroup B or C cluster following an initial serogroup B or C case respectively. To estimate the preventable burden of disease in a preschool setting, risks were calculated for these clusters with subsequent cases occurring between 2 and 28 days (assuming that even if prophylaxis is given it is unlikely to be administered quickly enough to prevent cases in days 0-1). Since the number of children attending preschool groups is higher than the number of places because many children attend part-time, the impact on the risk estimates of increasing the denominator by around 50\% was examined for this setting.

\section{RESULTS}

\section{Clusters}

A total of 114 clusters were reported in preschool and school settings in England and Wales between 1 April 1995 and 31 March 2001. Twenty were reported in preschool settings, 43

\begin{tabular}{|c|c|c|c|c|c|c|c|}
\hline Setting & $1995-96$ & 1996-97 & 1997-98 & 1998-99 & $1999-00$ & 2000-01 & Total \\
\hline \multicolumn{8}{|l|}{ Serogroup $\mathrm{C}$ alone } \\
\hline Preschool & - & 1 & - & 1 & 2 & - & 4 \\
\hline Primary & 2 & 2 & - & - & 2 & - & 6 \\
\hline Secondary & 4 & 3 & 3 & 8 & 1 & - & 19 \\
\hline Independent & 1 & - & - & - & - & - & 1 \\
\hline Total C & 7 & 6 & 3 & 9 & 5 & 0 & 30 \\
\hline \multicolumn{8}{|l|}{ Serogroup B alone } \\
\hline Preschool & - & - & 1 & 1 & 3 & 1 & 6 \\
\hline Primary & - & - & 4 & - & 2 & 6 & 12 \\
\hline Secondary & - & 1 & 2 & - & 1 & 3 & 7 \\
\hline Total B & 0 & 1 & 7 & 1 & 6 & 10 & 25 \\
\hline \multicolumn{8}{|c|}{ Serogroup mixed B and C } \\
\hline Preschool & - & 1 & - & - & - & - & 1 \\
\hline Primary & - & - & - & 2 & - & - & 2 \\
\hline Secondary & - & 2 & 1 & - & 1 & - & 4 \\
\hline Total mixed B and $C$ & 0 & 3 & 1 & 2 & 1 & 0 & 7 \\
\hline \multicolumn{8}{|l|}{ Other confirmed ${ }^{*}$} \\
\hline Preschool & - & - & - & 1 & - & - & 1 \\
\hline Primary & - & 1 & 2 & 2 & - & - & 5 \\
\hline Secondary & 2 & 1 & 1 & 1 & - & - & 5 \\
\hline Independent & - & - & - & - & - & - & - \\
\hline Total other & 2 & 2 & 3 & 4 & - & - & 11 \\
\hline Total & 9 & 12 & 14 & 16 & 12 & 10 & 73 \\
\hline
\end{tabular}




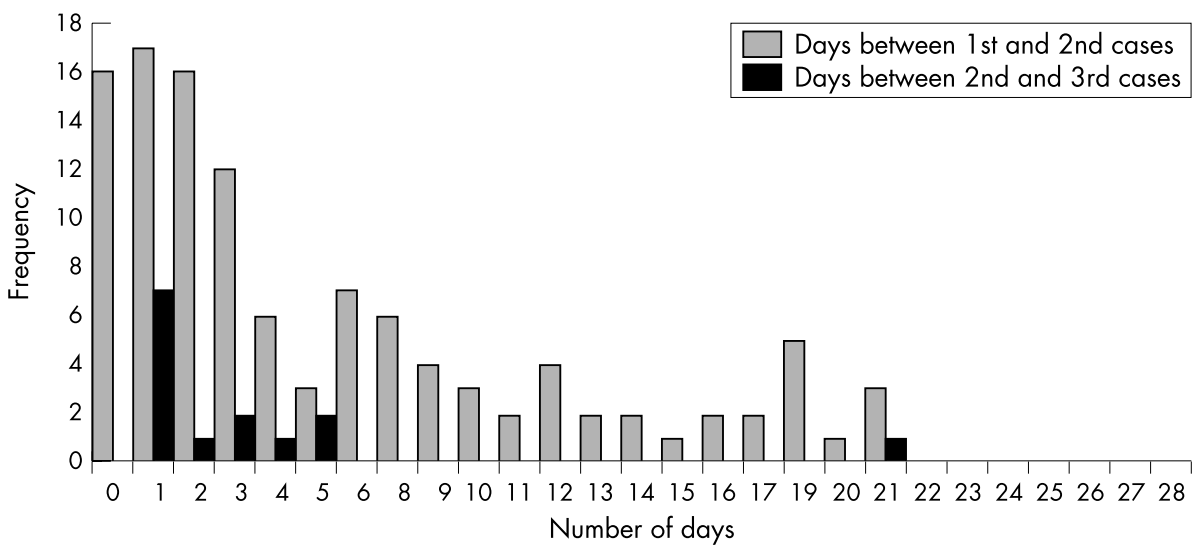

Figure 1 Frequency of interval in days between 1 st and 2 nd, and 2 nd and 3 rd cases in clusters of meningococcal disease in England and Wales, from April 1995 to March 2001. in primary, 46 in secondary, and five in independent schools. The majority $(86 \%)$ clusters had only two cases, 13 clusters had three cases, and the remaining three clusters had four, five, and nine cases respectively. Seventy three (64\%) clusters were confirmed; $30(40 \%)$ were serogroup C clusters-that is, contained at least two cases caused by serogroup C strains (table 2). Most serogroup C clusters occurred in secondary schools, whereas most serogroup B clusters were in primary schools. No serogroup C clusters occurred in any setting between April 2000 and March 2001.

Fifteen serogroup C and eight serogroup B clusters had further strain characterisation on two or more cases. In each of these clusters the strains were indistinguishable. Twelve serogroup C clusters were serotype 2a (six serosubtype P1.5, six were not typeable), and three were seroytpe $2 \mathrm{~b}$ (all serosubtype P1.5 P1.3). Three serogroup B clusters were serotype 4 (one serosubtype P1.15, two serosubtype P1.4), two were serotype l (l serosubtype P1.4, one no further typing), and two had no serotyping data but were serosubtypes P1.6 and P1.5.

The time interval between the initial and subsequent cases ranged between 0 and 21 days, with $29 \%$ of second cases occurring less than two days after a single case and $68 \%$ within the first seven days (fig 1). Subsequent cases occurred after 21 days of the initial case in three clusters, but by three weeks the estimates of relative risk in the fourth week were not raised above baseline. Of the 16 clusters with three or more cases, 15 of the third cases occurred within seven days of the second and one occurred after 21 days.

In $65(57 \%)$ of the clusters all cases occurred within the same class or school year. In six clusters, additional social links between the cases were identified and in two clusters in independent schools the cases shared accommodation. In the remaining 39 clusters no links were identified other than school.

Chemoprophylaxis (with or without vaccination) was given only to those in same class or school year in 26 clusters, with antibiotics given more widely to the whole institution in 64 clusters. In seven of the 30 serogroup C clusters, vaccination was given only to those in the same class or school year in seven, with widespread vaccination offered to the whole institution in 21 clusters.

\section{Risk estimates}

There was a statistically significant increased risk of occurrence of any type of cluster (confirmed, probable, serogroup B, C, or mixed serogroups) following any initial case of meningococcal disease relative to the background risk in all settings (table 3). The estimates of relative risk and absolute risk were highest in the preschool and lowest in the secondary school settings. In all settings, the relative risk for a confirmed cluster following an initial confirmed case was higher than the relative risk of any cluster following any case, and the absolute risk was marginally lower except in

Table 3 Risk estimates of occurrence of a cluster within four weeks for any cluster, a confirmed cluster, and a serogroup B and C cluster by setting, in England and Wales from April 1995 to March 2001

\begin{tabular}{|c|c|c|c|c|c|}
\hline Setting & Type of cluster & $\begin{array}{l}\text { Observed number } \\
\text { of clusters* }\end{array}$ & $\begin{array}{l}\text { Expected number } \\
\text { of clusters }\end{array}$ & $\operatorname{RR}(95 \% \mathrm{Cl})$ & AR per $100000(95 \% \mathrm{Cl})$ \\
\hline \multirow[t]{4}{*}{ Preschool } & Any & 20 & 0.725 & 27.6 (15.2 to 39.9$)$ & 69.9 (38.7 to 101.2$)$ \\
\hline & Confirmed & 11 & 0.327 & 33.6 (16.8 to 60.0$)$ & $57.3(28.7$ to 102.1$)$ \\
\hline & B & 6 & 0.135 & 44.5 (16.3 to 96.3$)$ & $48.6(17.8$ to 105.4$)$ \\
\hline & C & 4 & 0.042 & 95.2 (26.2 to 42.6$)$ & 61.6 (16.9 to 157.1$)$ \\
\hline \multirow[t]{4}{*}{ Primary } & Any & 43 & 7.910 & $5.4(3.8$ to 7.1$)$ & $5.7(4.0$ to 7.4$)$ \\
\hline & Confirmed & 22 & 2.495 & $8.8(5.1$ to 12.6$)$ & $5.2(3.0$ to 7.4$)$ \\
\hline & B & 12 & 0.739 & 16.2 (8.4 to 28.1$)$ & $5.2(2.7$ to 9.0$)$ \\
\hline & C & 6 & 0.511 & 11.7 (4.3 to 25.4 ) & 3.3 (1.2 to 7.2$)$ \\
\hline \multirow[t]{4}{*}{ Secondary } & Any & 46 & 12.849 & 3.6 (2.5 to 4.6$)$ & $3.0(2.1$ to 3.9$)$ \\
\hline & Confirmed & 31 & 5.209 & $5.9(3.8$ to 8.1$)$ & $3.2(2.0$ to 4.3$)$ \\
\hline & B & 7 & 1.032 & 6.8 (2.7 to 14.0$)$ & $1.6(0.6$ to 3.3$)$ \\
\hline & $\mathrm{C}$ & 16 & 1.671 & $9.6(5.4$ to 14.7$)$ & 3.1 (1.7 to 4.7$)$ \\
\hline \multirow[t]{4}{*}{ Independent } & Any & 5 & 0.965 & 5.2 (1.7 to 12.0$)$ & $5.4(1.7$ to 12.5$)$ \\
\hline & Confirmed & 2 & 0.338 & 5.9 (0.7 to 21.3$)$ & $3.6(0.4$ to 13.1$)$ \\
\hline & B & 0 & 0.089 & $0(0.0$ to 41.7$)$ & $0(0.0$ to 13.1$)$ \\
\hline & C & 1 & 0.082 & $12.2(0.3$ to 67.9$)$ & $3.9(0.1$ to 21.7$)$ \\
\hline
\end{tabular}

$R R$, relative risk; $A R$, absolute risk.

*The observed number of confirmed, B, and C clusters reported here differ from those in table 2 as only clusters in which subsequent cases are the same serogroup or classification (confirmed) as the initial case have been included. 
Table 4 Risk estimates for occurrence of a cluster between 2 and 28 days for any cluster, a confirmed cluster, and a serogroup B and C cluster in a preschool setting, in England and Wales from April 1995 to March 2001

\begin{tabular}{lllll}
\hline $\begin{array}{l}\text { Type of } \\
\text { cluster }\end{array}$ & $\begin{array}{l}\text { Observed number } \\
\text { of clusters }\end{array}$ & $\begin{array}{l}\text { Expected number } \\
\text { of clusters }\end{array}$ & RR $(95 \%$ CI) & AR per 100000 (95\% CI) \\
\hline Any & 14 & 0.670 & $20.8(11.6$ to 34.2$)$ & $49.0(27.3$ to 80.4$)$ \\
Confirmed & 8 & 0.300 & $26.4(11.4$ to 52.1$)$ & $41.7(18.0$ to 82.3$)$ \\
B & 4 & 0.130 & $31.9(8.8$ to 81.4$)$ & $32.4(8.9$ to 82.7$)$ \\
C & 3 & 0.039 & $76.9(15.9$ to 225.4$)$ & $46.2(9.6$ to 135.6$)$ \\
\hline
\end{tabular}

secondary schools. The relative risk of a serogroup C cluster following an initial $C$ case was higher than for a serogroup B cluster following an initial B in all settings except primary schools, although the combined estimate of risk across all settings was very similar (RR 11.7 and 12.5 respectively). None of these differences were statistically significant. Using an inflated denominator of 0.9 million (mean group size 38 ) for preschools, the relative risk of any further cases was estimated as 15.4 (95\% CI 11.0 to 28.9), still higher than other settings. Risk estimates for clusters occurring between 2 and 28 days after a single case in pre school settings remained high (table 4). There was no significant increase in risk of clusters occurring between 21 and 27 days in any setting (data not shown).

\section{DISCUSSION}

In this study of over 100 clusters of meningococcal disease, we showed an increased short term risk of further cases in preschool and school settings and provided robust estimates of relative and absolute risk. Although serogroup C clusters were mainly due to serotype 2 a strains, a phenotypic marker for the virulent ET37 clonal complex, ${ }^{12}$ the overall risk of a cluster was similar for serogroup B and C disease. Following implementation of the UK meningococcal serogroup C vaccination programme that started in November $1999^{13}$ and offered MenC vaccine to everyone $0-17$ years of age, no serogroup C clusters were reported in 2000-01.

The estimates of relative risk of a cluster occurring in a preschool or primary school setting in England and Wales in this study are higher than previously reported, ${ }^{8}$ even after adjustment for under-reporting and seasonality. This may reflect both improved ascertainment in recent years and a truly increased risk of clusters associated with the higher incidence of serogroup C disease since 1995. ${ }^{9}$ In most clusters, subsequent cases occurred within one week of the initial case, and by three weeks the estimates of relative risk had returned to baseline. This suggests that our definition of a cluster (cases within four weeks) was adequate.

The higher risk of clusters in a preschool setting than in a school remained after allowing for inaccuracies in the denominator data. If true, the reasons for higher risk are unclear. Susceptibility is higher in young children but meningococcal carriage rates are very low in this age group, ${ }^{14}$ and another study found the risk of primary cases of meningococcal disease among children attending day care in Ireland was lower than among children not attending day care. $^{4}$

Clusters of meningococcal disease represent only a small proportion of all cases occurring in England and Wales each year, yet they cause high levels of public and professional anxiety. ${ }^{12}$ Cases in $89 \%$ of confirmed clusters with known serogroup were caused by strains of the same serogroup, and those for which further strain characterisation was reported were all microbiologically indistinguishable. This suggests that for clusters where the strain is known for only one case, it is likely that other cases are due to the same strain and the clusters should be managed accordingly, rather than await microbiological confirmation of a link between cases. ${ }^{7}$ We were not able to measure the impact of preventive measures in this study; however, the high risk of further cases before antibiotic prophylaxis in this and other cluster series ${ }^{15}$ and the short interval between second and subsequent cases, support the need for urgent public health action. ${ }^{6}$

Despite the higher risk shown in this study, the revised UK guidelines do not recommend prophylaxis in preschool or school settings after a single case. ${ }^{7}$ The effectiveness of widespread chemoprophylaxis in these settings in preventing further cases is not known. Failures of such measures to prevent further cases both within and beyond four weeks following a single case have been reported. ${ }^{8}$ The possible benefits of widespread use of chemoprophylaxis in the management of single cases and clusters must be balanced against factors other than financial and personnel costs. The negative effects of widespread antibiotic use, particularly adverse effects of medication, development of antibiotic resistance, and elimination of the possibly protective Neisseria lactamica strains ${ }^{16}$ from the nasopharynx must be considered. $^{7}$

In practice, the time between onset of disease for the first case and implementation of chemoprophylactic measures would mean that cases occurring within 48 hours of the initial case would not be preventable. In this study, 29\% of subsequent cases occurred within 48 hours of the initial case.

In the preschool setting, the absolute risk excluding $0-1$ days was estimated as $1 / 2000$ - that is, 2000 would need to be treated if efficacy is $100 \%$ (or around 4000 using the revised denominator data). The actual number of clusters is small, around three per year in England and Wales, and chemoprophylaxis would need to be given to about 70 preschool groups to prevent one cluster. Evidence of risk reduction is needed to inform policy decisions on the use of more widespread antibiotic prophylaxis after single cases of meningococcal disease.

\section{ACKNOWLEDGEMENTS}

We would like to thank CCDCs, infection control nurses, information officers, and regional epidemiologists for completing and returning questionnaires. We also thank Usha Gungabissoon at CDSC and staff at the HPA Meningococcal Reference Unit for providing microbiological data.

\section{Authors' affiliations}

K L Davison, J M White, M E Ramsay, N S Crowcroft, Immunisation Department, HPA Communicable Disease Surveillance Centre, London NW9 5EQ, UK

N Andrews, HPA Communicable Disease Surveillance Centre, London NW9 5EQ, UK

A A Rushdy, Department of Health, Skipton House, London SE1 6AH, UK 
E B Kaczmarski, HPA Meningococcal Reference Unit, Withington Hospital, Manchester M20 2LR, UK

P N Monk, Leicestershire Northamptonshire \& Rutland Strategic Health Authority, Leicester LE5 4QF, UK

J M Stuart, South West, The Wheelhouse, Bond's Mill, Stonehouse, Gloucestershire GL10 3RF, UK

\section{REFERENCES}

1. Ardern K, Bowler S, Hussey RM, et al. Managing meningococcal disease case clusters: art or science? J Epidemiol Community Health 1999;53:565-71.

2 Stuart JM. Managing outbreaks - the public health response. In: Pollard AJ Maiden MC, eds. Methods in molecular medicine, Vol. 67: Meningococcal disease: methods and protocols. Totowa: Humana Press Inc., 2002:257-72.

3 Begg NT, Cartwright KA, Cohen J, et al. Consensus statement on diagnosis, investigation, treatment and prevention of acute bacterial meningitis in immunocompetent adults. British Infection Society Working Party. J Infect 1999;39:1-15.

4 Grein T, O'Flanagan D. Day-care and meningococcal disease in young children. Epidemiol Infect 2001;127:435-41.

5 Stuart JM, Monk PN, Lewis DA, et al. Management of clusters of meningococcal disease. PHIS Meningococcus Working Group and Public Health Medicine Environmental Group. Commun Dis Rep CDR Rev 1997;7:R3-5.

6 PHLS Meningococcal Infections Working Group and Public Health Medicine Environmental Group. Control of meningococcal disease: guidance for consultants in communicable disease control. Commun Dis Rep CDR Rev 1995; 5:R189-95.
7 Public Health Laboratory Service, Public Health Medicine Environmental Group, Scottish Centre for Infection and Environmental Health. Guidelines for public health management of meningococcal disease in the UK. Commun Dis Public Health 2002;5:187-204.

8 Hastings L, Stuart J, Andrews N, et al. A retrospective survey of clusters of meningococcal disease in England and Wales, 1993 to 1995: estimated risks of further cases in household and educational settings. Commun Dis Rep CDR Rev 1997;7:R195-200.

9 Ramsay ME, Collins M, Rush M, et al. The epidemiology of meningococcal disease in England and Wales, 1996 and 1997. Eurosurveillance 1997;2:1-2.

10 Shigematsu M, Davison KL, Charlett A, et al. National enhanced surveillance of meningococcal disease in England, Wales and Northern Ireland, January 1999-June 2001. Epidemiol Infect 2002;129:459-70.

11 Francis B, Green M, Payne C. The GLIM System: release 4 manual. Oxford: Clarendon Press, 1994.

12 Maiden MC, Feavers IM. Meningococcal typing. J Med Microbiol 1994:40:157-8

13 Miller E, Salisbury D, Ramsay M. Planning, registration, and implementation of an immunisation campaign against meningococcal serogroup $C$ disease in the UK: a success story. Vaccine 2001;20(suppl 1):S58-67.

14 Cartwright KA, Stuart JM, Jones DM, et al. The Stonehouse survey: nasopharyngeal carriage of meningococci and Neisseria lactamica. Epidemiol Infect 1987;99:591-601.

15 Zangwill KM, Schuchat A, Riedo FX, et al. School-based clusters of meningococcal disease in the United States. Descriptive epidemiology and a case-control analysis. JAMA 1997:277:389-95.

16 Gold R, Goldschneider I, Lepow ML, et al. Carriage of Neisseria meningitidis and Neisseria lactamica in infants and children. J Infect Dis 1978;137:112-21. 